\title{
Physicochemical properties of house and cave edible bird's nest from Southern Thailand
}

\author{
Kasidate Chantakun $^{\mathrm{a}}$, Hideki Kishimura ${ }^{\mathrm{b}}$, Yuya Kumagai ${ }^{\mathrm{b}}$, Soottawat Benjakula,** \\ a International Center of Excellence in Seafood Science and Innovation (ICE-SSI), Faculty of Agro-Industry, Prince of \\ Songkla University, Hat Yai, Songkhla 90110 Thailand \\ b Laboratory of Marine Chemical Resource Development, Faculty of Fisheries Sciences, Hokkaido University, \\ Hakodate, Hokkaido 041-8611 Japan
}

${ }^{*}$ Corresponding author, e-mail: soottawat.b@psu.ac.th

\begin{abstract}
This investigation aimed at examining physicochemical properties and characteristics of house and cave edible bird's nest (EBN) collected from locations in Southern Thailand. The house EBN and the cave EBN samples were gathered from eight provinces in Southern Thailand. Color, proximate composition, mineral, nitrate, nitrite sialic acid (Sia-a) content, amino acid composition, and microbial load of all the collected samples were determined. Protein was the major component found in both the house EBN (52.68-54.73\%) and the cave EBN (52.65-55.25\%). Nonessential amino acids, i.e., aspartic acid/asparagine and serine; and essential amino acids, i.e., leucine, threonine, and phenylalanine, were dominant amino acids for both EBN. The average Sia-a content of the house EBN (3570 mg/100 g) was higher than that of the cave EBN $(3128.7 \mathrm{mg} / 100 \mathrm{~g})$. On the other hand, higher calcium, nitrate, and nitrite contents were found in the cave EBN. However, the microbiological quality of all the samples was within the limits issued by the Thai National Bureau of Agricultural Commodity and Food Standards. The quality of the EBN samples is varied depending on the production origin or geographical location. EBN is recommended as a high-quality animal product rich in Sia-a and amino acids.
\end{abstract}

KEYWORDS: house edible bird's nest, cave edible bird's nest, Southern Thailand, proximate composition, sialic acid

\section{INTRODUCTION}

Edible bird's nest (EBN), or "Caviar of the East", is a well-known nutritious Chinese traditional cuisine $[1,2]$. EBN is made of saliva secretion produced by Aerodramus fuciphagus and Aerodramus maximus, commonly known as white-nest and black-nest swiftlets, respectively [3]. Swiftlet is an aerial insectivore bird. The main resources for the insects are forests, grasslands, and rice fields. Different resource locations with a variety of insects determine nutrient compositions of the EBN [4]. The major constituents of EBN are protein (58.6-66.9\%), followed by carbohydrate (24.3-31.4\%), ash (0.5-9.4\%), and lipid (0.01$1.2 \%)[1,3,5-7]$.

Traditionally, EBN is collected from caves by indigenous habitats in Southeast Asia, especially in the limestone caves. The aforementioned places had the world's largest population of swiftlets before overharvesting, which dramatically reduced their population $[1,3]$. With augmenting demand and price for EBN since the 1990s, swiftlet houses have been built in Indonesia, Malaysia, and Thailand to mitigate the shortage of cave EBN [8]. Since cave EBN has been considered being more valuable or more health-beneficial than house EBN, the former has a higher price than the latter [1]. In fact, the cave EBN generally contains more foreign materials and feathers than the house EBN. The texture of the house EBN is usually smoother as compared with that of the cave EBN [9]. In addition, the house EBN has fewer feathers and other contaminants in comparison to the cave EBN [10]. Different chemical compositions of EBN (house EBN and cave EBN) from various geographical origins and production sites have been documented [3]. Their physicochemical properties, proximate compositions, amino acid compositions, and Sia-a, nitrate, nitrite, and mineral contents were varied $[3,6,7,11]$. EBN from some regions of Malaysia, Vietnam, and Indonesia was analyzed. Marcone [1] reported that protein was the major component of EBN from Malaysia and Indonesia. Generally, house EBN had higher protein content than cave EBN. For Sia-a, Quek et al [3] documented that house EBN showed a higher content than cave EBN. Feed source, swiftlet species, and harvest season could contribute to the quality of EBN. In addition, calcium (Ca) and sodium (Na) are the major minerals found in the EBN samples. Seow et al [11] found that Ca was the main element in the cave EBN samples. On the other hand, the house EBN sample showed a higher Na content than the cave EBN. Jamalluddin et al [12] reported that house EBN from Malaysia showed lower nitrate and nitrite contents than cave EBN. Although the Southern Thailand has been known to be a famous production site for high-prized EBN, no information on differences between house and cave EBN exists.

Thus, this work aimed to study physicochemical properties and characteristics of EBN from Southern Thailand and to determine the quality of EBN from 


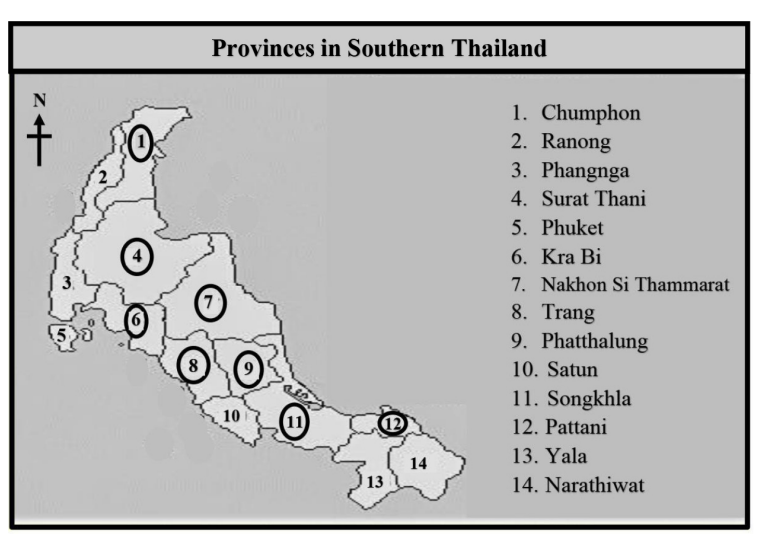

Fig. 1 Eight locations (circled) in Southern Thailand where the house and the cave EBN samples were collected.

various geographical origins and production sites.

\section{MATERIALS AND METHODS}

\section{Chemicals}

All chemicals were of analytical grade. Standard $\mathrm{N}$-acetylneuraminic acid (Sia-a) was procured from Sigma-Aldrich Chemical Co. (St. Louis, MO, USA). Acetonitrile, water, methanol (HPLC Grade), tetrahydrofuran, and phosphoric acid were purchased from Lab-Scan (Bangkok, Thailand). Microbial media were purchased from Oxoid Ltd. (Hampshire, England).

\section{Edible bird's nest (EBN)}

EBN samples were collected from eight different production origins and geographical locations in Southern Thailand, covering both sides of the southern peninsula including the Andaman Sea and the Gulf of Thailand. Basically, both house EBN and cave EBN were collected based on their availability and abundance. House EBN samples were collected from four provinces $(n=14$, each): two on the Central Gulf Coast, Surat Thani (ST-H) and Nakhon Si Thammarat (NT-H); and two on the Southern Gulf Coast, Songkhla (SK-H) and Pattani (PT-H). Cave EBN samples were collected from four provinces $(n=12$, each): Krabi $(\mathrm{KB}-\mathrm{C})$ and Trang (TR-C) on the Southern Andaman Coast; Phatthalung (PL-C) on the Southern Gulf Coast; and Chumphon (CP-C) on the Central Gulf Coast. The collection was done during the years 2019 and 2020. Fig. 1 shows the location of selected provinces where the EBN samples were collected. The EBN samples were cleaned with distilled water for $60 \mathrm{~min}$, and then foreign materials, e.g., eggshells, feathers, were removed. Subsequently, the prepared EBN samples were dried at $25 \pm 2{ }^{\circ} \mathrm{C}$ and relative humidity $(\mathrm{RH})$ of $48-50 \%$ for $48 \mathrm{~h}$. The dried samples were blended using a blender (Panasonic, Model MX-898N, Berkshire, UK) and then sieved using a sieve shaker (AS 200; Retsch, Haan, Germany) (sieve size: 18 mesh). Homogenous flakes were kept in a plastic container at $4 \pm 2{ }^{\circ} \mathrm{C}$ until further use for analysis.

\section{Color}

The color of the EBN flakes was measured using a colorimeter (Color Flex, Hunter Lab Inc., Reston, VA, USA). $L^{*}, a^{*}$, and $b^{*}$-values were recorded by Chantakun and Benjakul [5].

\section{Water activity}

The water activity $\left(\mathrm{a}_{\mathrm{w}}\right)$ of samples was determined using water activity meter (4TEV, Aqualab, Pullman, WA, USA).

\section{Proximate compositions}

Protein, moisture ash, and fat contents were analyzed following the AOAC analytical methods [13]. Carbohydrate content was calculated based on subtraction as tailored by Chantakun and Benjakul [5].

\section{Mineral contents}

The atomic absorption spectrometer (Perkin Elmer Analyst 100, Waltham, USA) was used to determine sodium $(\mathrm{Na})$, magnesium $(\mathrm{Mg})$, calcium $(\mathrm{Ca})$, and potassium (K) contents as detailed by Quek et al [3]. Standard curves for individual elements were prepared separately from the stock solution with different concentration ranges. The contents were reported as $\mathrm{mg} / \mathrm{kg}$ (dry weight basis).

\section{Nitrite and nitrate contents}

The method of Zatar et al [14] was adopted for the determination of nitrite and nitrate contents. The calculation was done using the standard curves of nitrite and nitrate with the concentration ranges of 0 50 and $0-100 \mathrm{mg} / \mathrm{ml}$, respectively. The contents were expressed as $\mathrm{mg} / \mathrm{kg}$ (dry weight basis).

\section{Sialic acid (Sia-a) content}

Sia-a content was measured as tailored by Feng et al [15]. Three milligrams of EBN sample were hydrolyzed with $1 \mathrm{ml}$ of $0.5 \mathrm{M}$ Na-bisulfate solution at $80^{\circ} \mathrm{C}$ for $30 \mathrm{~min}$. To the hydrolysate, $1 \mathrm{ml}$ of $O$-phenylenediamine dihydrochloride solution $(20 \mathrm{mg} / \mathrm{ml})$ was added. The mixture was heated in a water bath for $40 \mathrm{~min}$ at $80^{\circ} \mathrm{C}$ to achieve pre-column derivatization. A $20 \mu \mathrm{l}$ of the derivatized solution was filtered and subjected to a high-performance liquid chromatography, Agilent technologies 1200 series (Santa Clara State, USA) coupled with a fluorescence detector. Separation of Sia-a was done using a Water Sunfire C18 column $(150 \times 4.6 \mathrm{~mm}$ id., $5 \mu \mathrm{m})$ at $35^{\circ} \mathrm{C}$ and a flow rate of $1 \mathrm{ml} / \mathrm{min}$. The mobile phases used were (A) $1.0 \%(\mathrm{v} / \mathrm{v})$ tetrahydrofuran aqueous solution consisting of $0.15 \%(\mathrm{v} / \mathrm{v})$ phosphoric acid and (B) acetonitrile with a ratio of $\mathrm{A}: \mathrm{B}=95: 5$. The excitation and emission wavelengths of the 
fluorescence detector for Sia-a quantification using $\mathrm{N}$-acetylneuraminic acid (0-1000 $\mathrm{mg} / \mathrm{l})$ as standard were at 230 and $425 \mathrm{~nm}$, respectively. Sia-a content was expressed as $\mathrm{mg} / 100 \mathrm{~g}$ (dry weight basis).

\section{Amino acid composition}

Amino acid composition of EBN was analyzed by an amino acid analyzer (MLC-703; Atto Co., Tokyo, Japan) as described by Sinthusamran et al [16].

\section{Microbiological count}

Total variable count (TVC) was determined following the protocol of the Food and Drug Administration [17]. The sample (10 g) was transferred to a stomacher bag filled with $90 \mathrm{ml}$ saline solution $(0.85 \%, \mathrm{w} / \mathrm{v})$. After being mixed for 1 min using a stomacher blender (Stomacher M400, Seward Ltd., Worthington, England), a serial dilutions were done using a saline solution. TVC was measured by pour plate with incubation for $48 \mathrm{~h}$ at $37^{\circ} \mathrm{C}$. Mold count was enumerated on potato dextrose agar incubated at $25^{\circ} \mathrm{C}$ for 3 days. Staphylococcus aureus, Salmonella spp., Escherichia coli, and Bacillus cereus were determined as per the procedure of BAM [17].

\section{Statistical analysis}

A completely randomized design (CRD) was implemented for the entire studies. All the experiments and analyses were done in triplicates. For pair comparisons, the $t$-test was used. One-way analysis of variance (ANOVA) was used, and Duncan's multiple range test was carried out to analyze the significant differences among samples at a level of $p<0.05$ using SPSS version 11.0 (SPSS Inc., Chicago, IL, USA). Before analysis, the experiment was reviewed by the ethical committee (ethical number FIRIn 2562/023) of Prince of Songkla University, Hat Yai, Thailand.

\section{RESULTS AND DISCUSSION}

\section{Proximate compositions}

Proximate compositions including moisture, protein, carbohydrate, ash, and fat are shown in Table 1 . The moisture content of all EBN samples ranged from 15.60 to $17.69 \%$. Basically, moisture content of EBN should be below 15\% (based on Thai National Bureau of Agricultural Commodity and Food Standards: Bird's Nest [18], namely TNBACF-std-EBN. The high moisture content in all EBN samples might be the result of washing process. After drying process, some water was still trapped inside the structure of EBN. In general, moisture content varies among the dried ENB, depending on drying temperature and drying method [3]. No difference in the average moisture content was noticed between the house EBN and the cave EBN. Similar data were reported by Saengkrajang et al [7] that the moisture contents of house EBN collected from various regions (Eastern, Western, and Southern Thailand) were different $(p<0.05)$, and the values were in the range of $19.0-24.3 \%$.

Protein is the major component of the house and the cave EBN, constituting 52.68-57.73 and 52.65$54.74 \%$, respectively. Carbohydrate (20.27-21.54 and 20.05-23.16\%), ash (6.88-7.92 and 6.07-9.67\%), and fat $(0.19-0.57$ and $0.15-0.33 \%)$ of the two EBN were also reported. The results were in line with those of Linh et al [19] who documented that the highest nutritional component found in the EBN from the house farm and the cave in different regions was protein (49.4-51.17\%), followed by carbohydrate (36.93$38.53 \%)$. The high protein content of EBN reveals that swiftlets live in an environment with abundant feed at the specific location [2, 7, 10]. Quek et al [3] reported that the differences in environmental conditions such as temperature, relative humidity, feeding behavior, and light intensity, etc. between the cave EBN and the house EBN affected the EBN quality. On the other hand, all the samples had low ash and fat contents. Habitat, feed, and environmental conditions might affect those compositions of EBN. Overall, no differences in average proximate compositions (protein, carbohydrate, ash, and fat) were found between cave the EBN and the house EBN samples $(p>0.05)$ in the present study.

\section{Color}

The color of the house EBN and the cave EBN from different locations is shown in Table 1. All samples showed different $\mathrm{L}^{*}, \mathrm{a}^{*}$, and $\mathrm{b}^{*}$-values $(p<0.05)$ as influenced by different locations in Southern Thailand. The higher average $L^{*}$-values (lightness) of the house EBN were noticeable, compared with those of the cave EBN $(p<0.05)$. On the other hand, the $\mathrm{a}^{*}$ (redness) and $\mathrm{b}^{*}$-values (yellowness) of the cave EBN samples (KB-C, PL-C, CP-C, and TR-C) were higher than those of the house EBN samples (ST-H, SK-H, NT-H, and PT$\mathrm{H})$ as shown in Fig. 2. When compared, the average $a^{*}$ and $b^{*}$-values of the house EBN were lower than those of the cave EBN ( $p<0.05)$. Color is an essential quality attribute of EBN. The price of EBN with higher redness or yellowness was higher than that of white EBN because the consumers consider the colored nest to possess higher nutritive value and greater mineral contents [3]. Coincidentally, Jamalluddin et al [12] also reported the redder and yellower color of EBN collected from the cave than the house counterpart. Quek et al [3] documented that $L^{*} a^{*}$, and $b^{*}$-values of EBN samples in Malaysia were varied $(p<0.05)$, depending on production origins. The yellowish and reddish coloration is attributed to the migration or absorption of natural minerals from cave limestone into EBN in conjunction with iron oxidation [20]. However, the yellow/red color found in the cave EBN might be due to the oxidation of iron absorbed from the cave. Iron could be migrated into the nest through cave 
Table 1 Proximate compositions, color, and water activity of the house and the cave EBN collected from various locations in Southern Thailand.

\begin{tabular}{|c|c|c|c|c|c|c|c|c|c|}
\hline \multirow[t]{2}{*}{ Sample } & \multicolumn{5}{|c|}{ Proximate composition $(\%)^{\dagger}$} & \multicolumn{3}{|c|}{ Color } & \multirow{2}{*}{$\begin{array}{l}\text { Water } \\
\text { activity }\end{array}$} \\
\hline & Moisture & Protein & Carbohydrate & Ash & Fat & $L^{*}$ & $a^{*}$ & $b^{*}$ & \\
\hline ST-H & $17.69 \pm 0.18^{\mathrm{a}}$ & $52.68 \pm 0.29^{d}$ & $21.52 \pm 0.34^{b}$ & $7.92 \pm 0.37^{\mathrm{b}}$ & $0.19 \pm 0.0$ & ${ }^{d} 69.62 \pm 0.69^{c}$ & $-1.33 \pm 0.08^{\mathrm{e}}$ & $7.75 \pm 0.22^{g}$ & $0.66 \pm 0.02^{\mathrm{a}}$ \\
\hline $\mathrm{K}-\mathrm{H}$ & & $54.61 \pm 0.53^{\mathrm{ab}}$ & $21.54 \pm 0.66^{\mathrm{b}}$ & $7.89 \pm$ & $0.36 \pm 0.0$ & $73.66 \pm 0.46^{b}$ & $-0.65 \pm 0.06^{\mathrm{d}}$ & $10.05 \pm$ & $0.59 \pm 0.01^{\mathrm{a}}$ \\
\hline $\mathrm{T}-\mathrm{H}$ & & ${ }^{b} 54.22 \pm 0.42^{b c}$ & $21.53 \pm 1.19^{b}$ & $6.93 \pm$ & $0.39 \pm 0.04^{\mathrm{b}}$ & $67.83 \pm 0.43^{d}$ & $-0.57 \pm 0.05^{\mathrm{d}}$ & $11.49 \pm$ & $0.59 \pm 0.01^{\mathrm{a}}$ \\
\hline T-H & 17.5 & $54.73 \pm 0.86^{\mathrm{ab}}$ & $20.27 \pm 0.61^{b c}$ & $6.88 \pm 0.44^{\mathrm{c}}$ & $0.57 \pm 0.09^{\mathrm{a}}$ & $77.27 \pm 1.20^{\mathrm{a}}$ & $-1.26 \pm 0.10^{\mathrm{e}}$ & $7.66 \pm 0.39^{g}$ & $0.66 \pm 0.13^{\mathrm{a}}$ \\
\hline $\mathrm{B}-\mathrm{C}$ & 16.33 & ${ }^{c} 52.65 \pm 0.60^{d}$ & $22.92 \pm 0.46^{\mathrm{a}}$ & $7.95 \pm 0.10^{\mathrm{b}}$ & $0.15 \pm 0.02^{\mathrm{d}}$ & $66.15 \pm 1.30^{\mathrm{e}}$ & $0.58 \pm 0.05^{c}$ & $16.14 \pm 0.42^{c}$ & $0.59 \pm 0.00^{\mathrm{a}}$ \\
\hline $\mathrm{L}-\mathrm{C}$ & 16.4 & ${ }^{c} 55.25 \pm 0.24^{\mathrm{a}}$ & $20.05 \pm 0.88^{c}$ & $8.13 \pm 0.97^{\mathrm{b}}$ & $0.16 \pm 0.01^{\mathrm{d}}$ & $66.54 \pm 0.7$ & $1.65 \pm 0.18^{\mathrm{b}}$ & $19.28 \pm$ & $0.63 \pm 0.01^{\mathrm{a}}$ \\
\hline $\mathrm{P}-\mathrm{C}$ & 15.7 & $54.74 \pm 0.22^{\mathrm{ab}}$ & $23.16 \pm 0.52^{\mathrm{a}}$ & $6.07 \pm 0.67^{d}$ & $0.33 \pm 0.04^{\mathrm{b}}$ & $61.63 \pm 0.66^{\mathrm{f}}$ & $1.50 \pm 0.02^{\mathrm{b}}$ & $14.17 \pm 0.22^{\mathrm{d}}$ & $0.59 \pm 0.02^{\mathrm{a}}$ \\
\hline TR-C & $16.08 \pm 0.34^{\mathrm{bc}}$ & ${ }^{c} 53.46 \pm 0.18^{\mathrm{cd}}$ & ${ }^{d} 20.52 \pm 0.33^{b c}$ & $9.67 \pm 0.58^{a}$ & $0.27 \pm 0.03^{c}$ & $60.97 \pm 1.35^{f}$ & $2.66 \pm 0.12^{\mathrm{a}}$ & $18.16 \pm 0.70^{\mathrm{b}}$ & $0.64 \pm 0.01^{\mathrm{a}}$ \\
\hline House & $16.95 \pm 0.95^{\mathrm{A}}$ & $54.06 \pm 0.95^{\mathrm{A}}$ & $21.22 \pm 0.63^{\mathrm{A}}$ & $7.41 \pm 0.58^{\mathrm{A}}$ & $0.38 \pm 0.1$ & ${ }^{\mathrm{A}} 72.10 \pm 4.22^{\mathrm{A}}$ & $-0.95 \pm 0.40^{\mathrm{B}}$ & $9.24 \pm 1.87^{\mathrm{B}}$ & $0.63 \pm 0.04^{\mathrm{A}}$ \\
\hline ave & $16.13 \pm 0.3$ & $54.03 \pm 1.19^{\mathrm{A}}$ & $21.51 \pm 1.47^{\mathrm{A}}$ & $7.96 \pm 1.4$ & $0.23 \pm 0$ & $63.82 \pm 2.93^{B}$ & $1.60 \pm 0.85^{\mathrm{A}}$ & 争 & $.61 \pm 0.03^{\mathrm{A}}$ \\
\hline
\end{tabular}

House EBN from: Surat Thani (ST-H); Songkhla (SK-H); Nakhon Si Thammarat (NT-H); and Pattani (PT-H). Cave EBN from: Krabi (KB-C); Phatthalung (PL-C); Chumphon (CP-C); and Trang (TR-C). Values are presented as mean \pm standard deviation $(n=3)$.

${ }^{\dagger}$ Wet weight basis. Different lowercase and uppercase superscripts in the same column indicate significant differences $(p<0.05)$.

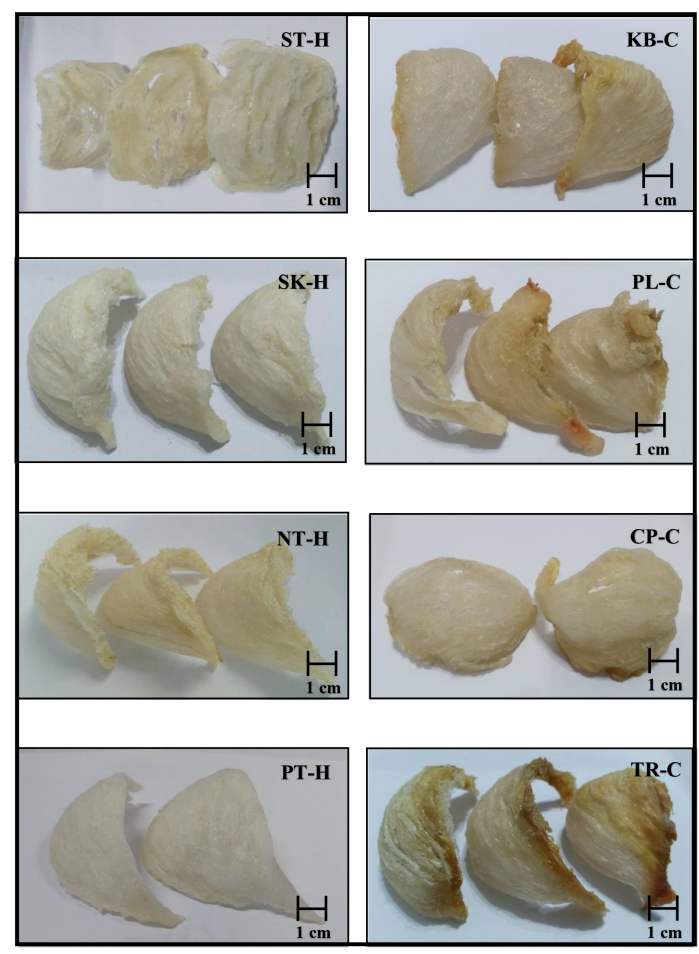

Fig. 2 Photos of EBN samples from different provinces in Southern Thailand. House EBN from: Surat Thani (ST-H); Songkhla (SK-H); Nakhon Si Thammarat (NT-H); and Pattani (PT-H). Cave EBN from: Krabi (KB-C); Phatthalung (PL-C); Chumphon (CP-C); and and Trang (TR-C).

drippings accelerated by high humidity in the cave [7]. TR-C samples showed the highest $\mathrm{a}^{*}$-value, whereas PL-C had the highest $\mathrm{b}^{*}$-value $(p<0.05)$. Thus, the color of EBN varied, depending on the location or the habitat.

\section{Water activity}

The water activity of EBN collected from different locations in Southern Thailand is presented in Table 1. No difference in average water activity was observed between the cave EBN and the house EBN samples $(p>0.05)$. Additionally, all EBN samples showed no significant difference $(p>0.05)$ in water activity, which ranged from 0.59 to 0.66 . The result was in tandem with Quek et al [3] who documented a similar water activity between the house EBN and the cave EBN $(p>0.05)$, which ranged between 0.66 and 0.68 . Normally, dried products with a water activity of less than 0.60 are microbiologically stable. If they are still not completely dried, their shelf-life can be shortened, caused by microbial spoilage [21]. Thus, the drying process of EBN was very important for prolonging its shelf-life during distribution and storage.

\section{Mineral contents}

Mineral compositions of EBN samples are shown in Table 2. Calcium (Ca) and sodium (Na) were the main minerals in all the samples, followed by magnesium $(\mathrm{Mg})$ and potassium $(\mathrm{K})$. All the house EBN samples had higher $(p<0.05)$ Na content $(968.82-$ $1266.35 \mathrm{mg} / 100 \mathrm{~g}$ ) than the cave EBN (264.90$743.20 \mathrm{mg} / 100 \mathrm{~g})$. On the contrary, the Ca content of the cave EBN $(949.40-1930.50 \mathrm{mg} / 100 \mathrm{~g})$ was higher than that of the house EBN (493.65$800.20 \mathrm{mg} / 100 \mathrm{~g}$ ), especially from the cave of Phatthalung Province (PL-C), which exhibited the highest content $(p<0.05)$. According to Quek et al [3] and Saengkrajang et al [7], Ca was the dominant element in cave EBN samples with average contents of $1723.1-1677.0 \mathrm{mg} / 100 \mathrm{~g}$. Moreover, the house 
EBN samples showed high content of $\mathrm{Na}$ (840.0$53.6 \mathrm{mg} / 100 \mathrm{~g}$ ) $[5,11]$. When the average $\mathrm{Na}$ and Ca contents between the cave EBN and the house EBN were compared, the cave EBN had a lower average $\mathrm{Na}$ content and a higher $\mathrm{Ca}$ content than the house EBN $(p<0.05)$. Nevertheless, no differences in average $\mathrm{Mg}$ and $\mathrm{K}$ contents were observed between both groups of the samples. Generally, major minerals required for human beings are listed in the descending order: $\mathrm{Ca}>\mathrm{Na}>\mathrm{Mg}>\mathrm{K}[6]$. For the cave EBN samples, Ca:Na:Mg:K ratio was 101:13:6:1, while the ratio of $46: 33: 8: 1$ was recorded for the house EBN samples [11]. The differences in element types and contents between both sample groups were governed by the different environments and conditions between caves and houses, where the nests were attached or glued [11]. The recommended dietary allowance (RDA) of $\mathrm{Mg}$ and $\mathrm{Ca}$ is 420 and $1000 \mathrm{mg}$ /day for adult men and 320 and $1200 \mathrm{mg}$ /day for adult women, respectively [5]. Thus, a portion of EBN (100 g) could yield an RDA of $23-31 \%$ for $\mathrm{Mg}$ and $45-55 \%$ for Ca.

\section{Nitrite and nitrate contents}

Table 2 shows the nitrite and the nitrate contents of EBN samples collected from different locations in Southern Thailand. The nitrite and the nitrate contents of the house EBN samples were 28.69-47.83 and $225.58-1944.25 \mathrm{mg} / \mathrm{kg}$, respectively. The cave EBN showed a higher nitrite and nitrate contents of 120.85-218.18 and 8982.44-21769.4 mg/kg, respectively, compared with the house EBN. The nitrite and nitrate contents of the house EBN and the cave EBN from different locations were different $(p<0.05)$. According to Quek et al [3], the nitrite and the nitrate contents in EBN from different production origins were drastically varied, of which the house EBN showed a lower content of nitrite $(31.63 \mathrm{mg} / \mathrm{kg})$ and nitrate $(133.43 \mathrm{mg} / \mathrm{kg})$ than the cave EBN $(702.0$ and $31992 \mathrm{mg} / \mathrm{kg}$, respectively). Similarly, Jamalluddin et al [12] documented that the cave EBN from Malaysia possessed higher nitrate and nitrite contents than the house EBN. The nitrite content of $5.7 \mu \mathrm{g} / \mathrm{g}$ was detected in the house EBN, while the content of $843.8 \mu \mathrm{g} / \mathrm{g}$ was found in the cave EBN. For nitrate, the house EBN and the cave EBN showed the contents of 98.2 and $36999.4 \mu \mathrm{g} / \mathrm{g}$, respectively. Normally, nitrite and nitrate contents in cave EBN are often greater than those of the house EBN due to the uncontrolled environment or conditions (temperature, $\mathrm{RH}$, and sanitation) in stone caves that contribute to the elevation of nitrite and nitrate levels in EBN through anaerobic bacteria fermentation or nitrification [3, 20]. The amount of bird soil and guano in the house EBN were lower than the cave EBN. In the cave, guanos from various birds, bats, and other organic mixture had high nitrite and nitrate contents [1]. Hence, the cave EBN had a higher average nitrite and nitrate contents than the house EBN $(p<0.05)$. High levels of nitrite and nitrate are found to be a major problem of EBN [10]. Based on the TNBACF-std-BN, nitrite in EBN should not be higher than $30 \mathrm{mg} / \mathrm{kg}$. In the present study, both nitrite and nitrate contents of the samples exceeded the standard limit. Thus, further process is still needed for both compounds to comply with the TNBACF-std-BN.

\section{Sialic acid (Sia-a) content}

Sia-a is the general term of acyl derivatives of neuraminic acid [22]. Among all the forms, $N$ acetylneuraminic acid was the main Sia-a found in EBN [23]. Table 2 displays the Sia-a contents in the house EBN and the cave EBN samples collected from different locations. Noticeably, the house EBN samples had a higher average Sia-a content (3570 mg/100 g) than the cave EBN (3128.7 mg/100 g). However, no differences in average Sia-a content were found between both groups of the samples $(p>0.05)$. Quek et al [3] also found that Sia-a contents of the house EBN and the cave EBN collected from different locations in Malaysia were different with the former showing a higher content $(13.6 \%)$ than the latter (8.3\%) (dry weight basis) $(p<0.05)$. Similarly, Thavamanithevi et al [24] documented that Sia-a contents of the house EBN and the cave EBN collected from Eastern Malaysia varied (1-6\%), and the cave EBN possessed a lower Sia-a content than the house EBN. Generally, EBN is a natural food product rich in Sia-a $[1,25]$. Sia-a is the main factor for numerous cellular functions, preventing influenza infections, and cellular fluid uptake [23]. Zhou et al [26] documented that Sia-a acts as a self-associated pattern for maintaining the baseline of innate immune cells. Recognizing receptors are a key factor in transmission of inhibitory signals to the immune system [23]. However, other food products also contain Sia-a, for example, Sia-a contents in crucian eggs, egg yolk, egg-white, cows' milk, and cheese were $0.45,0.11,0.03,0.02$, and $0.02 \%$ (wet weight basis), respectively [27]. Thus, the EBN was an important source of Sia-a and its content can be different among EBN samples, depending on the environment, the bird's feed, the geographical location, etc [1]. In the present study, NT-H, PT-H, and PL-C had higher Sia-a contents than the others $(p<0.05)$.

\section{Microbiological quality}

The microbiological quality of EBN from different locations in Southern Thailand is presented in Table 3. Based on the TNBACF-std-EBN [18], E. coli should not exceed $100 \mathrm{CFU} / g$; while B. cereus, S. aureus, and mold should not be above $1000 \mathrm{CFU} / \mathrm{g}$. All EBN samples from the eight provinces had microbial load under the standard limit. Although Salmonella spp. is not specified in the standard for EBN, it was not detected 
Table 2 Major mineral, nitrite, nitrate, and sialic acid contents of the house EBN and the cave EBN collected from various locations in Southern Thailand.

\begin{tabular}{lccccccc}
\hline Sample & \multicolumn{7}{c}{ Component } \\
\cline { 2 - 7 } & \multicolumn{1}{c}{ Sodium* } & \multicolumn{1}{c}{ Calcium* $^{*}$} & Magnesium* & \multicolumn{1}{c}{ Potassium* } & Nitrite* $^{*}$ & Nitrate* $^{*}$ & Sialic acid ** $^{*}$ \\
\hline ST-H & $1055.75 \pm 90.72^{\mathrm{b}}$ & $740.30 \pm 35.78^{\mathrm{de}}$ & $124.43 \pm 3.93^{\mathrm{d}}$ & $17.94 \pm 1.26^{\mathrm{d}}$ & $28.69 \pm 0.42^{\mathrm{g}}$ & $225.58 \pm 1.92^{\mathrm{g}}$ & $3460 \pm 30^{\mathrm{bc}}$ \\
SK-H & $1266.35 \pm 181.09^{\mathrm{a}}$ & $636.60 \pm 14.71^{\mathrm{e}}$ & $118.21 \pm 4.13^{\mathrm{d}}$ & $22.99 \pm 2.13^{\mathrm{ab}}$ & $37.88 \pm 0.44^{\mathrm{f}}$ & $1944.24 \pm 5.41^{\mathrm{d}}$ & $3280 \pm 10^{\mathrm{cd}}$ \\
NT-H & $968.82 \pm 27.24^{\mathrm{b}}$ & $493.65 \pm 15.34^{\mathrm{f}}$ & $143.87 \pm 10.28^{\mathrm{c}}$ & $26.20 \pm 1.15^{\mathrm{a}}$ & $47.83 \pm 0.17^{\mathrm{e}}$ & $1231.86 \pm 1.29^{\mathrm{e}}$ & $3880 \pm 180^{\mathrm{a}}$ \\
PT-H & $1264.65 \pm 46.74^{\mathrm{a}}$ & $800.20 \pm 35.92^{\mathrm{d}}$ & $118.21 \pm 5.65^{\mathrm{d}}$ & $18.83 \pm 1.56^{\mathrm{cd}}$ & $47.55 \pm 0.46^{\mathrm{e}}$ & $424.77 \pm 1.26^{\mathrm{f}}$ & $3670 \pm 110^{\mathrm{ab}}$ \\
KB-C & $743.20 \pm 17.07^{\mathrm{c}}$ & $1463.25 \pm 8.84^{\mathrm{b}}$ & $242.26 \pm 3.34^{\mathrm{a}}$ & $23.44 \pm 2.76^{\mathrm{b}}$ & $119.00 \pm 0.50^{\mathrm{d}}$ & $9675.32 \pm 6.01^{\mathrm{c}}$ & $2480 \pm 10^{\mathrm{e}}$ \\
PL-C & $507.90 \pm 24.61^{\mathrm{d}}$ & $1930.50 \pm 124.31^{\mathrm{a}}$ & $103.30 \pm 2.96^{\mathrm{e}}$ & $16.83 \pm 0.48^{\mathrm{d}}$ & $218.18 \pm 0.57^{\mathrm{a}}$ & $12843.7 \pm 2.94^{\mathrm{b}}$ & $3710 \pm 160^{\mathrm{ab}}$ \\
CP-C & $264.90 \pm 18.99^{\mathrm{e}}$ & $949.40 \pm 2.55^{\mathrm{c}}$ & $124.99 \pm 1.48^{\mathrm{d}}$ & $16.90 \pm 0.64^{\mathrm{d}}$ & $136.28 \pm 2.11^{\mathrm{b}}$ & $21769.4 \pm 21.3^{\mathrm{a}}$ & $3160 \pm 30^{\mathrm{d}}$ \\
TR-C & $675.90 \pm 38.99^{\mathrm{cd}}$ & $1053.40 \pm 27.58^{\mathrm{c}}$ & $168.75 \pm 10.64^{\mathrm{b}}$ & $21.75 \pm 0.78^{\mathrm{bc}}$ & $120.85 \pm 0.12^{\mathrm{c}}$ & $8982.44 \pm 9.77^{\mathrm{c}}$ & $3170 \pm 180^{\mathrm{d}}$ \\
\hline House & $1138.9 \pm 150.4^{\mathrm{A}}$ & $667.7 \pm 134.3^{\mathrm{B}}$ & $126.18 \pm 12.15^{\mathrm{A}} 21.49 \pm 3.83^{\mathrm{A}}$ & $40.49 \pm 9.12^{\mathrm{B}}$ & $956.6 \pm 789.2^{\mathrm{B}}$ & $3575 \pm 257^{\mathrm{A}}$ \\
EBN & & & & & & \\
\hline Cave & $548.0 \pm 213.1^{\mathrm{B}}$ & $1349.1 \pm 446.6^{\mathrm{A}}$ & $159.83 \pm 61.33^{\mathrm{A}} 19.73 \pm 3.38^{\mathrm{A}}$ & $148.58 \pm 47.04^{\mathrm{A}} 13317.7 \pm 5879.8^{\mathrm{A}}$ & $3130 \pm 504^{\mathrm{A}}$ \\
EBN & & & & & & \\
\hline
\end{tabular}

House EBN from: Surat Thani (ST-H); Songkhla (SK-H); Nakhon Si Thammarat (NT-H); and Pattani (PT-H). Cave EBN from: Krabi (KB-C); Phatthalung (PL-C); Chumphon (CP-C); and Trang (TR-C). Values are presented as mean \pm standard deviation $(n=3)$.

${ }^{\dagger}$ Wet weight basis. Different lowercase and uppercase superscripts in the same column indicate significant differences $(p<0.05)$.

* $\mathrm{mg} / \mathrm{kg}$ (dry weight basis); ** mg/100 g (dry weight basis).

Table 3 Microbial counts of EBN samples collected from various locations in Southern Thailand.

\begin{tabular}{lcccccccc}
\hline Microbiological quality & \multicolumn{9}{c}{ Sample } \\
\cline { 2 - 8 } & ST-H & SK-H & NT-H & PT-H & KB-C & PL-C & CP-C & TR-C \\
\hline Escherichia coli (CFU/g) & $<10$ & $<10$ & $<10$ & $<10$ & $<10$ & $<10$ & $<10$ & $<10$ \\
Staphylococcus aureus (CFU/g) & $1.8 \times 10^{2}$ & $1.2 \times 10^{2}$ & $3.1 \times 10^{2}$ & $1.5 \times 10^{2}$ & $1.0 \times 10^{2}$ & $2.1 \times 10^{2}$ & $2.6 \times 10^{2}$ & $1.4 \times 10^{2}$ \\
Bacillus cereus (CFU/g) & $<10$ & $<10$ & $<10$ & $<10$ & $<10$ & $<10$ & $<10$ & $<10$ \\
Mold count (CFU/g) & $1.2 \times 10^{2}$ & $1.0 \times 10^{2}$ & $2.5 \times 10^{2}$ & 50 & $2.5 \times 10^{2}$ & $3.0 \times 10^{2}$ & $1.5 \times 10^{2}$ & 50 \\
Total variable count (CFU/g) & $1.5 \times 10^{3}$ & $4.2 \times 10^{4}$ & $5.0 \times 10^{4}$ & $1.0 \times 10^{3}$ & $4.5 \times 10^{3}$ & $4.0 \times 10^{3}$ & $5.3 \times 10^{3}$ & $4.2 \times 10^{3}$ \\
Salmonella spp. (per 25 g) & Negative & Negative & Negative & Negative & Negative & Negative & Negative & Negative \\
\hline
\end{tabular}

House EBN from: Surat Thani (ST-H); Songkhla (SK-H); Nakhon Si Thammarat (NT-H); and Pattani (PT-H). Cave EBN from: Krabi (KB-C); Phatthalung (PL-C); Chumphon (CP-C); and Trang (TR-C).

Table 4 Amino acid compositions of EBN samples collected from various locations in Southern Thailand.

\begin{tabular}{|c|c|c|c|c|c|c|c|c|c|c|}
\hline \multirow{2}{*}{$\begin{array}{l}\text { Amino acid } \\
\text { (g/100 g sample) }\end{array}$} & \multicolumn{8}{|c|}{ Sample } & \multicolumn{2}{|c|}{ Average } \\
\hline & ST-H & SK-H & NT-H & PT-H & KB-C & PL-C & CP-C & TR-C & House EBN & Cave EBN \\
\hline Lysine & 4.56 & 4.53 & 4.51 & 4.53 & 4.55 & 4.54 & 4.49 & 4.59 & $4.53 \pm 0.02^{\mathrm{A}}$ & $4.54 \pm 0.04^{\mathrm{A}}$ \\
\hline Threonine & 8.57 & 8.38 & 8.05 & 8.55 & 8.23 & 8.13 & 8.52 & 8.16 & $8.39 \pm 0.24^{\mathrm{A}}$ & $8.26 \pm 0.18^{\mathrm{A}}$ \\
\hline Leucine & 8.37 & 8.49 & 8.61 & 8.66 & 8.68 & 8.60 & 8.44 & 8.51 & $8.53 \pm 0.13^{\mathrm{A}}$ & $8.56 \pm 0.10^{\mathrm{A}}$ \\
\hline Phenylalanine & 7.52 & 7.51 & 7.74 & 7.70 & 7.64 & 7.71 & 7.70 & 7.89 & $7.62 \pm 0.12^{\mathrm{A}}$ & $7.74 \pm 0.11^{\mathrm{A}}$ \\
\hline Isoleucine & 3.38 & 3.35 & 3.28 & 3.32 & 3.42 & 3.35 & 3.33 & 3.27 & $3.33 \pm 0.04^{\mathrm{A}}$ & $3.34 \pm 0.06^{\mathrm{A}}$ \\
\hline Valine & 7.55 & 7.64 & 7.77 & 7.68 & 7.61 & 7.73 & 7.69 & 7.73 & $7.66 \pm 0.09^{\mathrm{A}}$ & $7.69 \pm 0.06^{\mathrm{A}}$ \\
\hline Histidine & 4.32 & 4.21 & 4.50 & 4.36 & 4.20 & 4.63 & 4.44 & 4.56 & $4.35 \pm 0.12^{\mathrm{A}}$ & $4.46 \pm 0.19^{\mathrm{A}}$ \\
\hline Methionine & 0.86 & 0.81 & 0.78 & 0.78 & 0.40 & 0.52 & 0.74 & 0.74 & $0.81 \pm 0.04^{\mathrm{A}}$ & $0.60 \pm 0.17^{\mathrm{A}}$ \\
\hline Total EAA & 45.13 & 44.91 & 45.24 & 45.58 & 44.73 & 45.21 & 45.35 & 45.44 & $45.22 \pm 0.28^{\mathrm{A}}$ & $45.18 \pm 0.32^{\mathrm{A}}$ \\
\hline Serine & 9.47 & 9.58 & 9.62 & 9.39 & 9.42 & 9.52 & 9.65 & 9.62 & $9.52 \pm 0.10^{\mathrm{A}}$ & $9.55 \pm 0.10^{\mathrm{A}}$ \\
\hline Aspartic acid/asparagine & 10.87 & 10.91 & 10.90 & 10.95 & 10.96 & 10.85 & 10.76 & 10.84 & $10.91 \pm 0.03^{\mathrm{A}}$ & $10.85 \pm 0.08^{A}$ \\
\hline Tyrosine & 8.34 & 8.37 & 8.58 & 8.10 & 8.63 & 8.59 & 8.56 & 8.59 & $8.35 \pm 0.20^{\mathrm{A}}$ & $8.59 \pm 0.03^{\mathrm{A}}$ \\
\hline Glutamic acid/glutamine & 9.00 & 8.88 & 8.30 & 8.61 & 8.66 & 8.66 & 8.47 & 8.20 & $8.70 \pm 0.31^{\mathrm{A}}$ & $8.50 \pm 0.22^{\mathrm{A}}$ \\
\hline Arginine & 7.56 & 7.73 & 7.83 & 7.73 & 7.78 & 7.62 & 7.80 & 7.82 & $7.71 \pm 0.11^{\mathrm{A}}$ & $7.76 \pm 0.09^{\mathrm{A}}$ \\
\hline Cysteine & 1.78 & 1.66 & 1.60 & 1.58 & 1.67 & 1.68 & 1.66 & 1.65 & $1.66 \pm 0.09^{\mathrm{A}}$ & $1.67 \pm 0.01^{\mathrm{A}}$ \\
\hline Glycine & 4.51 & 4.57 & 4.57 & 4.61 & 4.67 & 4.46 & 4.43 & 4.50 & $4.57 \pm 0.04^{\mathrm{A}}$ & $4.52 \pm 0.11^{\mathrm{A}}$ \\
\hline Alanine & 3.34 & 3.39 & 3.36 & 3.45 & 3.48 & 3.41 & 3.32 & 3.34 & $3.39 \pm 0.05^{\mathrm{A}}$ & $3.39 \pm 0.07^{\mathrm{A}}$ \\
\hline Total NEAA & 54.87 & 55.09 & 54.76 & 54.42 & 55.27 & 54.79 & 54.65 & 54.56 & $54.79 \pm 0.28^{\mathrm{A}}$ & $54.82 \pm 0.32^{\mathrm{A}}$ \\
\hline
\end{tabular}

House EBN from: Surat Thani (ST-H); Songkhla (SK-H); Nakhon Si Thammarat (NT-H); and Pattani (PT-H). Cave EBN from: Krabi (KB-C); Phatthalung (PL-C); Chumphon (CP-C); and Trang (TR-C). Different uppercase superscripts in the same row indicate significant differences $(p<0.05)$. EAA, essential amino acids; NEAA, non-essential amino acids. 
(per $25 \mathrm{~g}$ sample) in all samples. In addition, the TVC of all samples was in the range of $1.0 \times 10^{3}-$ $5.0 \times 10^{4} \mathrm{CFU} / \mathrm{g}$. In the present study, microorganisms were still found in the dried EBN samples. Thus, additional processes, thermal or non-thermal, should be implemented to assure the safety for consumers.

\section{Amino acid compositions}

Amino acids serve as the nitrogenous backbones for proteins and several compounds such as neurotransmitters and hormones [28]. Based on a wet weight basis, proteins from EBN consisted of 17 amino acids: (1) non-essential amino acids (NEAA) serine, tyrosine, aspartic acid/asparagine, glutamic acid/glutamine, arginine, and cysteine; and (2) essential amino acids (EAA) valine, leucine, lysine, and isoleucine [5]. Amino acid compositions of the house EBN and the cave EBN samples from different locations in Southern Thailand are presented in Table 4. All the samples had leucine, threonine, and phenylalanine as the major EAA, while aspartic acid/asparagine and serine were dominant NEAA. It was noted that the content of NEAA (54.42-55.27 g/100 g sample) was higher than that of EAA (44.73-58 g/100 g sample). Overall, there was no difference in average content of all amino acids between the cave EBN and the house EBN samples $(p>0.05)$. According to Linh et al [19], the EBN from Vietnam had leucine and threonine as EAA, whereas aspartic acid and serine were the main NEAA. Quek et al [3] found that aspartic acid and asparagine were dominant amino acids in the EBN from Malaysia. Normally, the human body cannot synthesize EAA [5]. Chua et al [29] found that EBN had a higher concentration of EAA than other food products, e.g., quail egg, milk, and chicken. This result indicated that EBN is a good source of EAA enhancing the rate of protein synthesis in the human body [28].

\section{CONCLUSION}

House and cave EBN collected from eight provinces in Southern Thailand had a different quality, depending on geographical location. Protein and NEAA (aspartic acid/asparagine and serine) were major components for all the samples. The cave EBN had higher calcium, nitrite, and nitrate contents and lower Sia-a and sodium contents than the house EBN. Additionally, the cave EBN showed higher redness and yellowness associated with high content of iron. Those differences in composition and color between the house BN and the cave EBN could be used for sample differentiation. Overall, the microbial counts of all samples were in compliance with the Thai standards. Thus, EBN was a good source of Sia-a and amino acids with respect to health benefits.

Acknowledgements: The authors would like to express their sincere thanks to the Prince of Songkla University (Grant No. AGR6402088N) for financial support.

\section{REFERENCES}

1. Marcone MF (2005) Characterization of the edible bird's nest the "Caviar of the East". Food Res Int 38, 1125-1134.

2. Lee TH, Wani WA, Koay YS, Kavita S, Tan ETT, Shreaz $S$ (2017) Recent advances in the identification and authentication methods of edible bird's nest. Food Res Int 100, 14-27.

3. Quek MC, Chin NL, Yusof YA, Law CL, Tan SW (2018) Characterization of edible bird's nest of different production, species and geographical origins using nutritional composition, physicochemical properties and antioxidant activities. Food Res Int 109, 35-43.

4. Helmi-Subekti DT, Mranata B, Sudarnika E, Denny LW, Wibawan IWT (2018) Protein profile of edible bird's nest origin Kalimantan and Java Islands Indonesia. J Agric Vet Sci 11, 69-73.

5. Chantakun K, Benjakul S (2020) Effect of pretreatments and retort process on characteristics and sensory quality of edible bird's nest beverage. Int J Food Sci Technol 55, 2863-2871.

6. Norhayati M, Azman O, Wan Mohamud WN (2010) Preliminary study of the nutritional content of Malaysian edible bird's nest. Malays J Nutr 16, 389-396.

7. Saengkrajang W, Matan N, Matan N (2013) Nutritional composition of the farmed edible bird's nest (Collocalia fuciphaga) in Thailand. J Food Compos Anal 31, 41-45.

8. Connolly C (2016) 'A place for everything': Moral landscapes of 'swiftlet farming' in George Town, Malaysia. Geoforum 77, 182-191.

9. Dai Y, Cao J, Wang Y, Chen Y, Jiang L (2021) A comprehensive review of edible bird's nest. Food Res Int 140, ID 109875.

10. Wong Z, Chan GKL, Wu L, Lam H, Yao P, Dong T (2018) A comprehensive proteomics study on edible bird's nest using a new monoclonal approach and application in quality control. $J$ Food Compos Anal 66, 145-151.

11. Seow EK, Ibrahim B, Muhammad SA, Lee LH, Cheng LH (2016) Differentiation between house and cave edible bird's nests by chemometric analysis of amino acid composition data. LWT Food Sci Technol 65, 428-435.

12. Jamalluddin NH, Tukiran NA, Ahmad Fadzillah N, Fathi S (2019) Overview of edible bird's nests and their contemporary issues. Food Control 104, 247-255.

13. AOAC (2000) Official Method of Analysis of AOAC International, 17th edn, Association of Official Analytical Chemists, Washington DC.

14. Zatar NA, Abu-Eid MA, Eid AF (1999) Spectrophotometric determination of nitrite and nitrate using phosphormolybdenum blue complex. Talanta 50, 819-826.

15. Feng T, Xue C, Sun T, Cui H, Xu J (2010) Determination of sialic acid in edible bird's nest using pre-column derivatization reversed phase high performance liquid chromatography with photodiode array or fluorescence detection. $J$ Food Sci 31, 233-236.

16. Sinthusamran S, Idowu AT, Benjakul S, Prodpran T, Yesilsu AF, Kishimura H (2020) Effect of proteases and alcohols used for debittering on characteristics and antioxidative activity of protein hydrolysate from salmon frames. J Food Sci Technol 57, 473-483.

17. FDA (2001) Bacteriological analytical manual, In: Examination of Canned Foods, US Department 
of Health and Human Services, Food and Drug Administration, USA. Available at: https://www.fda.gov/Food/FoodScienceResearch/ LaboratoryMethods/ucm109398.html.

18. Thai National Bureau of Agricultural Commodity and Food Standard (2014) Thai Agricultural Standard: Bird's Nest TAS 6705-2014, Thailand. Available at: http:// www.moc.go.th.

19. Linh T, Son HL, Minh Ai H (2019) Nutritional content of Vietnamese edible bird's nest from selected regions. Eur J Nutr Food Saf 9, 66-71.

20. Paydar M, Wong YL, Wong WF, Hamdi OAA, Kadir NA, Looi CY (2013) Prevalence of nitrite and nitrate contents and its effect on edible bird's nest color. J Food Sci 78, 1940-1947.

21. Beuchat LR, Komitopoulou E, Beckers H, Betts RP, Bourdichon F, Fanning S, Joosten HN, Ter-Kuile BH (2013) Low-water activity foods: Increased concern as vehicles of foodborne pathogens. $J$ Food Prot 76, 150-172.

22. Kooner AS, Yu H, Chen X (2019) Synthesis of $N$ glycolylneuraminic acid (Neu5Gc) and its glycosides. Front Immunol 10, 1-24.

23. Schauer R (2009) Sialic acids as regulators of molecular and cellular interactions. Curr Opin Struct Biol 19, 507-514.
24. Thavamanithevi S, Sarifah R, Lim CG, Theanmalar M, Aidawati MS, Devi MD, Saleha AA (2014) Characterization and standardization of edible bird's nest (EBN)determination of sialic acid. Proc of the Edible Bird Nest Industry Conf, Putrajaya, pp 25-26.

25. Hamzah Z, Ibrahim N, Jaafar MN, Lee BB, Hussin K (2013) Nutritional properties of edible bird nest. J Asian Sci Res 3, 600-607.

26. Zhou X, Yang G, Guan F (2020) Biological functions and analytical strategies of sialic acids in tumor. Cells $\mathbf{9}$, ID 273.

27. Chen Y, Pan L, Liu N, Troy F, Wang B (2013) LCMS/MS quantification of $N$-acetylneuraminic acid, $N$ glycolylneuraminic acid and ketodeoxynonulosonic acid levels in the urine and potential relationship with dietary sialic acid intake and disease in 3- to 5-year-old children. Br J Nutr 111, 332-341.

28. Dalangin R, Kim A, Campbell RE (2020) The role of amino acids in neurotransmission and fluorescent tools for their detection. Int $J$ Mol Sci 21, ID 6197.

29. Chua P, Chan S, Bloodworth B, Li S, Leong L (2015) Identification of edible bird's nest with amino acid and monosaccharide analysis. J Agric Food Chem 63, 279-289. 